\title{
The Oxford study of Calcium channel Antagonism, Cognition, Mood instability and Sleep (OxCaMS): study protocol for a randomised controlled, experimental medicine study
}

Lauren Z. Atkinson ${ }^{1,2,3+}$, Lucy Colbourne ${ }^{1,2,3+}$, Alexander Smith ${ }^{1,2}$, Catherine H. Harmer ${ }^{1,2,3}$, Anna C. Nobre ${ }^{1,3,4}$, Jennifer Rendell ${ }^{1,2}$, Helen Jones ${ }^{1,2}$, Christopher Hinds ${ }^{1,5}$, Arne Mould ${ }^{1,2}$, Elizabeth M. Tunbridge 1,2, Andrea Cipriani ${ }^{1,2}$, John R. Geddes ${ }^{1,2}$, Kate E. A. Saunders ${ }^{1,2^{*}}$ and Paul J. Harrison ${ }^{1,2,3^{*}+}$ (D)

\begin{abstract}
Background: The discovery that voltage-gated calcium channel genes such as CACNA1C are part of the aetiology of psychiatric disorders has rekindled interest in the therapeutic potential of L-type calcium channel (LTCC) antagonists. These drugs, licensed to treat hypertension and angina, have previously been used in bipolar disorder, but without clear results. Neither is much known about the broader effects of these drugs on the brain and behaviour.

Methods: The Oxford study of Calcium channel Antagonism, Cognition, Mood instability and Sleep (OxCaMS) is a highintensity randomised, double-blind, placebo-controlled experimental medicine study on the effect of the LTCC antagonist nicardipine in healthy young adults with mood instability. An array of cognitive, psychiatric, circadian, physiological, biochemical and neuroimaging (functional magnetic resonance imaging and magnetoencephalography) parameters are measured during a 4-week period, with randomisation to drug or placebo on day 14 . We are interested in whether nicardipine affects the stability of these measures, as well as its overall effects. Participants are genotyped for the CACNA1C risk polymorphism rs1006737.
\end{abstract}

Discussion: The results will clarify the potential of LTCC antagonists for repurposing or modification for use in psychiatric disorders in which cognition, mood and sleep are affected.

Trial registration: ISRCTN, ISRCTN33631053. Retrospectively registered on 8 June 2018 (applied 17 May 2018).

Keywords: Bipolar disorder, Calcium blockers, Calcium channel antagonists, Depression, Functional magnetic resonance imaging, Magnetoencephalography, Mood instability, Sleep, Working memory

\footnotetext{
*Correspondence: kate.saunders@psych.ox.ac.uk;

paul.harrison@psych.ox.ac.uk

'Lauren Z. Atkinson, Lucy Colbourne, Kate E. A. Saunders and Paul J. Harrison contributed equally to this work.

'Department of Psychiatry, University of Oxford, Warneford Hospital, Oxford

OX3 7JX, UK

Full list of author information is available at the end of the article
}

(c) The Author(s). 2019 Open Access This article is distributed under the terms of the Creative Commons Attribution 4.0 International License (http://creativecommons.org/licenses/by/4.0/), which permits unrestricted use, distribution, and reproduction in any medium, provided you give appropriate credit to the original author(s) and the source, provide a link to the Creative Commons license, and indicate if changes were made. The Creative Commons Public Domain Dedication waiver (http://creativecommons.org/publicdomain/zero/1.0/) applies to the data made available in this article, unless otherwise stated. 


\section{Background}

L-type (voltage-gated) calcium channel (LTCC) antagonists (also called calcium blockers or calcium antagonists) such as verapamil and nifedipine are licensed and widely used to treat hypertension and angina. They have also been used sporadically in bipolar disorder and related conditions for more than 25 years $[1,2]$. The rationale was provided by diverse reports of altered calcium indices in patients with bipolar disorder and the fact that lithium carbonate, the standard treatment for the disorder, also affects calcium signalling $[3,4]$. A recent systematic review concluded that there is no good evidence for - or against - the efficacy of LTCC antagonists in bipolar disorder because there are virtually no controlled trials. Most of the data are observational or uncontrolled, limited to the manic phase of the illness and include results for drugs with uncertain or limited blood-brain barrier penetration [5].

Over the past decade strong evidence has emerged that LTCC genes, especially CACNA1C (which encodes the L-type $\mathrm{Ca}_{\mathrm{V}} 1.2 \alpha$ subunit), contribute to the aetiology of bipolar disorder and other psychiatric disorders as well as to phenotypes which are affected in these conditions such as memory and circadian rhythms $[6,7]$. These genomic findings have given new impetus to the study of LTCC antagonists as potential treatments for neuropsychiatric disorders [8]. Whilst the existing drugs are unlikely to be suitable for repurposing in this way, evidence that they can produce 'psychiatric' effects would provide an incentive to develop more selective drugs. The latter is a feasible goal because of the differential expression of individual LTCC genes and their isoforms in brain compared to heart and vasculature ([9] and Clark et al., bioRxiv 2018: 260562). At present there is virtually no information regarding behavioural or cognitive effects of current LTCC antagonists. Low-quality evidence has demonstrated potential beneficial effects on cerebrovascular cognitive impairment [10, 11]; an electronic health records study has suggested differential admission rates for persons taking LTCC antagonists for depression compared to people taking other antihypertensives [12], and some rodent studies have indicated improved performance on cognitive tasks after administration of LTCC antagonists [13-16].

Here we report an exploratory experimental medicine study of the LTCC antagonist nicardipine given to participants with high mood instability: OxCaMS (Oxford study of Calcium channel Antagonism, Cognition, Mood instability and Sleep). Mood instability was chosen as an inclusion criterion because it is a core feature of bipolar disorder and other disorders with which LTCCs are genetically associated [17]. In addition, it is present in a proportion of the general population $(\sim 14 \%)$ and correlated with poorer cognitive performance and with adverse health outcomes [17-19].
In brief, during a 14-day run-in phase, participants complete repeated assessments of cognition, mood and sleep, and undergo ambulatory electrocardiography (ECG) and actigraphy, functional magnetic resonance imaging (fMRI) of the brain and magnetoencephalography (MEG), as well as measurement of leukocyte LTCC gene expression and calcium flux. After 14 days, participants are randomised to nicardipine sustained release (SR) $30 \mathrm{mg}$ twice a day, or matched placebo, for another 14 days. During this period, all assessments and scans are repeated. The design allows for both between- and within-participant analyses. The overall goal is to determine the effects of LTCC antagonism on behaviour, mood instability, sleep, neural activity and calcium transport, as well as to assess target engagement of LTCCs in the brain.

\section{Methods/design}

The OxCaMS trial registration data are listed in Table 1, with an overview of the workflow shown in Fig. 1. The schedule of enrolment, interventions and assessments is shown in Fig. 2. The Standard Protocol Items: Recommendations for Interventional Trials (SPIRIT) checklist is Additional file 1; the current approved protocol (version 1.5) is Additional file 2. The approval letter is Additional file 3.

OxCaMS is a 4-week study, with a 2-week pre-randomisation phase, during which time a range of assessments are carried out, followed by randomisation and another 2-week period when the same assessments are continued or repeated whilst the participant takes the drug or placebo. The target recruitment is 40 participants.

Study visits take place at the National Institute for Health Research (NIHR) Oxford cognitive health Clinical Research Facility, with neuroimaging at the adjacent Oxford Centre for Human Brain Activity, part of the Wellcome Centre for Integrative Neuroimaging. Biochemical and genetic assays will be performed within the NIHR Oxford Health Biomedical Research Centre.

Randomisation utilises a computer-generated schedule implemented by a trial manager, who is based at the University of Oxford Department of Psychiatry and is external to the study. The randomisation algorithm minimises on gender, in a 1:1 allocation to either nicardipine SR or matched placebo. Dispensing is by Clinical Research Facility staff.

\section{Choice of drug and dosing regimen}

Nicardipine is a dihydropyridine LTCC antagonist, structurally similar to nifedipine [20]. It has strong evidence for good brain penetrability [21,22] and occupancy of central LTCCs after repeat dosing [21]. Nicardipine has reported beneficial effects in pre-clinical models of 
Table 1 Summary of OxCaMS trial registration data

\begin{tabular}{|c|c|}
\hline Data category & Information \\
\hline Registry and ID & ISRCTN33631053 \\
\hline Date of registration & 8 June 2018 \\
\hline Secondary identifying numbers & IRAS 213212 \\
\hline Sources of financial or material support & $\begin{array}{l}\text { Wellcome Trust, NIHR Oxford Health Biomedical Research Centre, } \\
\text { NIHR Oxford cognitive health Clinical Research Facility }\end{array}$ \\
\hline Sponsor & University of Oxford \\
\hline Contact for public queries & PJH (paul.harrison@psych.ox.ac.uk) or KEAS (kate.saunders@psych.ox.ac.uk) \\
\hline Contact for scientific queries & PJH (paul.harrison@psych.ox.ac.uk) or KEAS (kate.saunders@psych.ox.ac.uk) \\
\hline Public title & OxCaMS \\
\hline Scientific title & Oxford study of Calcium channel Antagonism, Cognition, Mood instability and Sleep \\
\hline Countries of recruitment & UK \\
\hline Health condition studied & Mood instability \\
\hline Intervention & Nicardipine sustained release (30 mg bd) or placebo, for 14 days \\
\hline Key inclusion criteria & $\begin{array}{l}\text { Score } \geq 7 \text { on Mood Disorder Questionnaire with evidence of functional impairment. } \\
\text { Aged } 18-35 \text { years }\end{array}$ \\
\hline Key exclusion criteria & $\begin{array}{l}\text { Current psychotropic medication. Need for urgent psychiatric treatment. } \\
\text { Psychiatric disorder or substance misuse which, in the opinion of the investigator, } \\
\text { could compromise safety or data quality }\end{array}$ \\
\hline Study type & $\begin{array}{l}\text { Primary purpose: experimental medicine, exploratory study } \\
\text { Allocation: randomised, double-blind, parallel group. } 14 \text { day run-in before allocation }\end{array}$ \\
\hline Date of first enrolment & December 2017 \\
\hline Target sample size & 40 \\
\hline Recruitment status & Recruiting \\
\hline Primary outcome & Cognitive variability \\
\hline Key secondary outcomes & $\begin{array}{l}\text { Mood variability, behavioural variability, BOLD and MEG signals at rest and } \\
\text { during task performance, sleep parameters, calcium channels in leukocytes }\end{array}$ \\
\hline
\end{tabular}

cerebral ischaemia [23], seizures [24] and brain ageing [25]. Nicardipine is a potent blocker of $\mathrm{Ca}_{\mathrm{V}} 1.2$ channels [26]. It is available in a sustained release formulation, allowing twice daily dosing, resulting in easier administration and a lower maximal concentration $\left(C_{\max }\right)$ which decreases the side effects associated with vasodilatation (e.g. flushing, headache). In a study of normotensive young adults, the investigational regimen used in OxCaMS (nicardipine SR, $30 \mathrm{mg}$ twice daily) was well tolerated and produced no significant effects on blood pressure or pulse [27].

\section{Patient and public involvement}

The plans for OxCaMS were presented at a public open day of the Oxford cognitive health Clinical Research Facility and NIHR Oxford Health Biomedical Research Centre. Patients were not involved in the design of the study.

\section{Participants}

Participants aged $18-35$ years are recruited via advertisement or from the Oxford Student Sleep Survey [28]. Inclusion criteria include scoring $\geq 7$ on the Mood
Disorder Questionnaire (MDQ) [29, 30], indicating a history of periods of unstable and elevated mood and reporting that these episodes have caused at least mild functional impairment. In a separate study, we have shown that an MDQ score of $>7$ correlates strongly with current, day-to-day mood variability (LZA, ACN, CHH, $\mathrm{PJH}$, unpublished observations).

Participants meeting the MDQ criterion are initially screened by online questionnaire to assess for exclusion criteria including use of psychotropic medication currently or within the past 12 weeks; any contraindication to nicardipine, or to MRI or MEG; and reported harmful use of alcohol or illicit drugs.

\section{Baseline screening}

Participants who pass the initial screening are invited to a pre-randomisation visit at which they are assessed for current or past psychiatric illness using the Mini International Neuropsychiatric Interview, version 5.0. Those meeting criteria for a disorder are not excluded, unless the clinician feels it might compromise safety or data quality. 


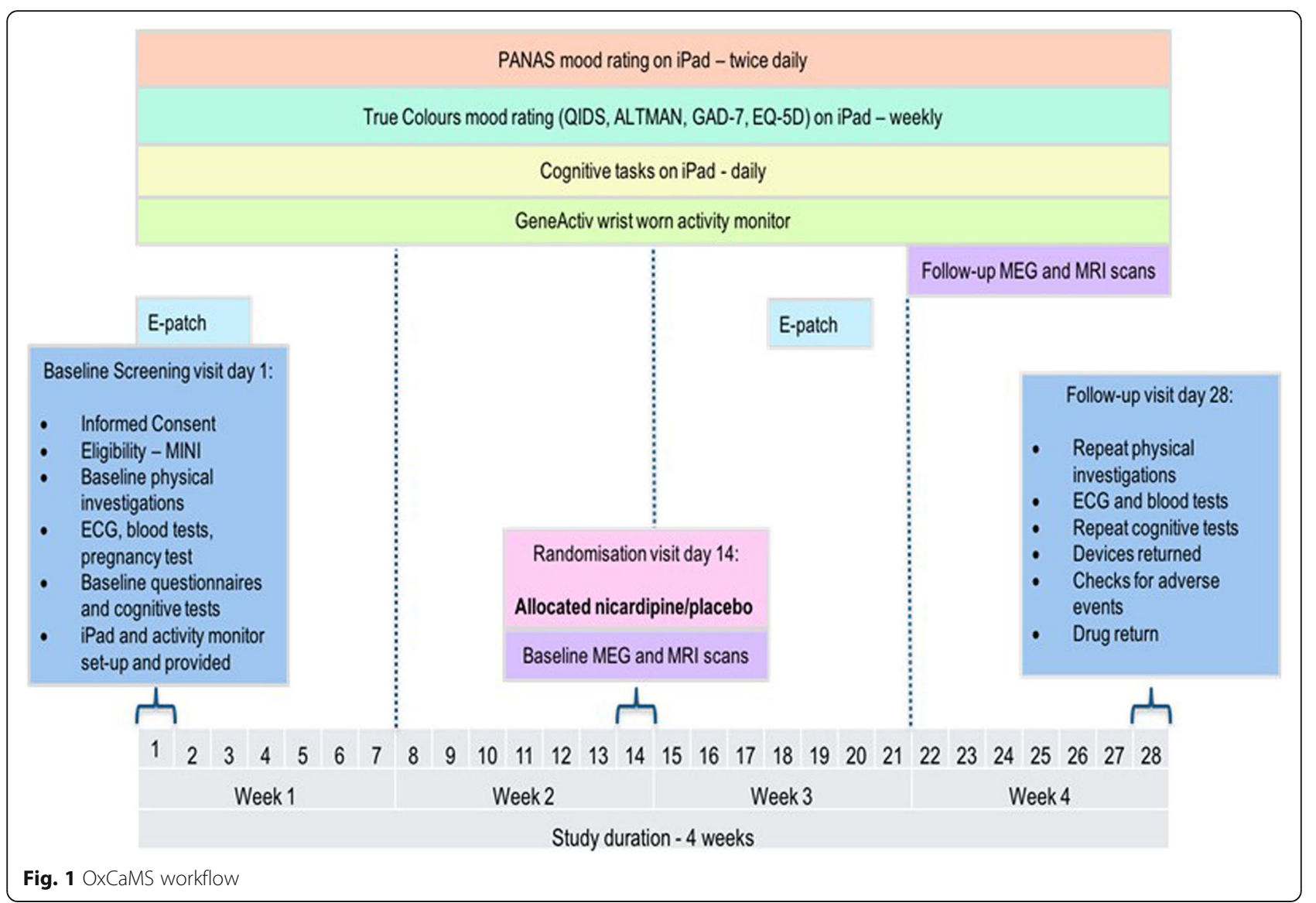

Demographic details are recorded and a number of screening tools completed, including the McLean Screening Instrument for Borderline Personality Disorder [31] and the Adult Attention Deficit Hyperactivity Disorder (ADHD) Self-Report Scale (ASRS-v1.1). Alcohol consumption is assessed using the Alcohol Use Disorders Identification Test (AUDIT). Several self-report questionnaires are completed via an iPad, including the Barratt Impulsiveness Scale, the Affective Lability Scale (short form), the Affect Intensity Measure, the Morningness-Eveningness Questionnaire [32] and the Sleep Condition Indicator (SCI-R; [33]). A physical examination is carried out and vital signs and an electrocardiogram recorded. Blood is taken for routine analyses (including full blood count, urea and electrolytes, thyroid function, inflammatory markers) and for calcium channel gene expression and calcium signalling studies. Women of childbearing age have a pregnancy test. Participants also complete a battery of cognitive tasks and are instructed in the use of an iPad for completion of daily cognitive testing and mood monitoring, as described in the following sections. With the participants' consent, their general practitioners are informed of their involvement in the study.

\section{Cognitive testing}

A range of novel and standardised tasks measure aspects of cognition twice during the study-at baseline screening and at study endpoint:

- The theory of visual attention (TVA) framework quantifies fundamental parameters of information processing and attention: visual perception threshold, processing speed, capacity of visual short-term memory, attentional control and spatial bias of attention [34]. The TVA framework has been used widely in healthy participants [35-37] and in various cognitively impaired clinical populations [38, 39], but not in mood disorders.

- Two tasks from the emotional test battery (ETB) [40] examine emotional processing: the facial expression recognition test and emotional word categorisation. These tasks have been used in multiple experimental medicine studies and have been found to be reliable predictors and markers of antidepressant treatment response.

- The Stop-Signal Task assesses impulsivity and behavioural inhibition [41]. Stop-signal reaction times have been shown to increase with impulsivity 


\begin{tabular}{|c|c|c|c|c|c|c|}
\hline & \multicolumn{6}{|c|}{ STUDY PERIOD } \\
\hline & Enrolment & Screening & $\begin{array}{c}\text { Pre- } \\
\text { randomisation }\end{array}$ & Randomisation & $\begin{array}{c}\text { Post- } \\
\text { randomisation }\end{array}$ & Final Visit \\
\hline TIMEPOINT (day) & $-t_{1}$ & 1 & $2-13$ & 14 & $15-27$ & 28 \\
\hline Eligibility Screen & $\mathrm{X}$ & & & & & \\
\hline Informed Consent & & $\mathrm{x}$ & & & & \\
\hline Demographic data & & $\mathrm{X}$ & & & & \\
\hline Medical History & & $\mathrm{X}$ & & & & \\
\hline Current Medication & & $\mathrm{X}$ & & $\mathrm{X}$ & & \\
\hline Allocation & & & & $\mathrm{X}$ & & \\
\hline \multicolumn{7}{|c|}{ INTERVENTIONS: } \\
\hline Nicardipine & & & & $\bullet$ & & $\Rightarrow$ \\
\hline \multirow{2}{*}{\multicolumn{7}{|c|}{ ASSESSMENTS: }} \\
\hline & & & & & & \\
\hline McLean Screening Instrument & & $\mathrm{X}$ & & & & \\
\hline Adult ADHD Self-Report Scale & & $\mathrm{X}$ & & & & \\
\hline $\begin{array}{r}\text { Alcohol Use Disorders } \\
\text { Identification Test }\end{array}$ & & $\mathrm{x}$ & & & & \\
\hline Barratt Impulsiveness Scale & & $\mathrm{X}$ & & & & \\
\hline Affective Lability Scale & & $\mathrm{X}$ & & & & \\
\hline Affect Intensity Measure & & $\mathrm{X}$ & & & & \\
\hline Sleep Condition Indicator & & $\mathrm{X}$ & & & & $\mathrm{X}$ \\
\hline $\begin{array}{r}\text { Morningness-Eveningness } \\
\text { Questionnaire }\end{array}$ & & $\mathrm{x}$ & & & & $\mathrm{x}$ \\
\hline Daily PANAS Questionnaire & & $\bullet$ & & & & $\rightarrow$ \\
\hline Weekly Mood Questionnaire & & $\mathrm{x}$ & $x$ & & $\mathrm{x}$ & $\mathrm{X}$ \\
\hline Daily cognitive tasks ${ }^{a}$ & & $\diamond$ & & & & $\rightarrow$ \\
\hline N-back task & & $\mathrm{X}$ & & & & $\mathrm{x}$ \\
\hline Stop-Signal Task & & $\mathrm{X}$ & & & & $x$ \\
\hline Emotional Test Battery & & $\mathrm{X}$ & & & & $\mathrm{X}$ \\
\hline Theory of Visual Attention task & & $\mathrm{x}$ & & & & $\mathrm{x}$ \\
\hline National Adult Reading Test & & $\mathrm{X}$ & & & & \\
\hline Physical investigations & & $\mathrm{x}$ & & & & $\mathrm{x}$ \\
\hline Blood samples & & $\mathrm{X}$ & & & & $\mathrm{X}$ \\
\hline E-patch remote ECG & & $x^{b}$ & & & $X^{c}$ & \\
\hline GENEactiv accelerometer & & $\bullet$ & & & & $\rightarrow$ \\
\hline MRI and MEG scans & & & & $\mathrm{X}$ & & $X$ \\
\hline
\end{tabular}

${ }^{a}$ Wheel of Fortune; Whack-a-T, Fractals (see text for details).

${ }^{\mathrm{b}}$ Days 1-3. 'Days 17-19.

Fig. 2 SPIRIT schedule

and to vary across mood episodes of bipolar disorder [42].

- The N-Back task of working memory. This task is well validated, and performance is sensitive to drug manipulation (see e.g. [43]).

- The National Adult Reading Test (NART; [44]) is used as a measure of verbal IQ.

In addition to these tests, each day during the 4-week study period participants complete three novel app-based games on an iPad which they are given, delivered via the True Colours platform:

- The first is a simple gambling game ('Wheel of Fortune'). On each trial, participants choose between two wheels, each divided into two segments proportional to the probability of winning or losing the amount of money specified in the segment. The aim of the task is to maximise the amount of 'money' that can be won over a session (total of 20 trials).
- The second game, 'Fractals', assesses reward learning. Each fractal is associated with a constant reward magnitude and reward probability. Participants learn to pick the most rewarding stimulus, ideally by integrating information about these two parameters. Each day participants are presented with 10 pairwise choices and 5 free choices in which all fractals are available to choose. In addition, participants are asked to guess how many points each fractal is worth ('reward magnitude') and how likely it is that points will be won ('reward probability' scale). Participants are allocated one set of 5 fractals before randomisation, and a new set of fractals after randomisation, to assess any differences in learning associated with nicardipine administration.

- The final game, 'Whack-A-T', assesses contextual cueing and implicit learning. It is based on a previously published task [45]. Participants are presented with an array of 11 'L's and one ' $\mathrm{T}$ ' and asked to tap on the ' $\mathrm{T}$ ' as quickly as possible. There 
are three conditions: (1) novel - in which 20 different configurations are presented per day but never repeated, (2) daily - in which 20 different configurations are presented once per day, every day and (3) within-day - in which there are 20 repetitions of a configuration within a day, but they are not repeated on another day.

Happiness is rated before and after each game on a 21 -point scale, from unhappy (-10), through neutral (0), to happy (10). Participants are emailed each day with a reminder to complete the tasks. Adherence is monitored via the True Colours system (see below); if a participant misses tasks for 2 or more days in succession, he/she is prompted by the study team.

\section{Mood instability}

Two measures of mood are recorded throughout the study. The Positive and Negative Affect Schedule, short form (PANAS-SF) is used for twice daily mood ratings. This 10-item self-report scale, which participants complete on the iPad, has high validity and reliability [46, 47] and has been widely used in healthy volunteer studies. To complement the PANAS ratings, the True Colours online self-management system (https://oxfordhealth.truecolours.nhs.uk/www/en/) is used to collect weekly mood ratings using clinically validated scales: the Quick Inventory of Depressive Symptomatology, self-report (QIDS-SR 16 ) [48], the Altman Self-Rating Mania Scale [49], the Generalised Anxiety Disorder assessment (GAD-7) [50] and the EuroQol 5-dimension (EQ-5D) quality of life measure [51]. Our primary interest is in the effect of calcium channel antagonism on mood instability rather than in mood per se (although the latter is also recorded); instability will be quantified using statistical approaches described later.

\section{Sleep}

Sleep is measured in a number of ways. As noted, participants complete the SCI-R and the Morningness-Eveningness Questionnaire at study baseline and at the final visit. They are also provided with a sleep diary for the study duration. These self-report sleep data will supplement the sleep data collected from ambulatory physiological monitoring (see subsequent sections).

\section{Actigraphy}

Wrist-worn GENEActiv accelerometers are worn by participants for the study duration to continuously measure activity, light and body temperature. The data will help us to estimate the duration, timing and quality of sleep, as well as provide information about physical activity and light exposure.

\section{Remote ECG and blood pressure monitoring}

Remote ECG is captured using the ePatch, a small, body-worn sensor that adheres to the skin. An ePatch will be fitted to participants at the baseline screening visit to wear for up to $72 \mathrm{~h}$ (maximum recording time). A second ePatch is provided to participants at the randomisation visit, with instruction to apply it 3 days after commencing nicardipine or placebo. The ePatch data allow us to explore the effect of nicardipine on heart rate variability and how this relates to mood instability and activity [52]. Participants are also given a portable blood pressure monitor and asked to record their daily blood pressure to assess any effects of nicardipine over the course of the randomised phase.

\section{LTCC gene expression and calcium signalling}

Circulating leukocytes variably express calcium channel genes [53], and calcium signalling plays a central role in leukocyte activation and cytokine release. LTCCs in particular modulate activation of specific T cell subsets [54]; thus, nicardipine may have direct effects on $\mathrm{T}$ cell function and cytokine production. Moreover, peripheral inflammation has been implicated in mood disorders [55].

We will assess the effects of nicardipine on leukocyte function. First, LTCC expression in blood (in the samples taken at baseline and during the randomised phase) will be measured using quantitative reverse transcriptase-polymerase chain reaction for the encoding messenger RNAs. We will also assess the suitability of available LTCC subunit antibodies for immunoblotting. Second, we will determine the effect of nicardipine on intracellular free calcium stores and calcium transients in peripheral blood mononuclear cells. Basal calcium levels and stimulated calcium transients will be measured separately in monocytes and T cells, identified by immunolabelling, using a fluorescence-activated cell sorting method that utilises Fura Red calcium dye [56]. We will also assay circulating levels of interleukin-6 (IL-6) and other inflammatory biomarkers.

\section{Functional magnetic resonance imaging}

Functional magnetic resonance imaging (fMRI) is used to explore the effects of calcium channel antagonism on neural dynamics and their variability, assessed using the blood oxygenation level dependent (BOLD) response. Participants are scanned at rest (eyes open) and whilst performing the gambling task described previously ( $30 \mathrm{~min})$ and a gender discrimination emotional facial expression task ( $12 \mathrm{~min})$. We include an arterial spin labelling (ASL) sequence to help distinguish cerebrovascular from neural effects of nicardipine.

MRI is carried out on a Siemens $3 \mathrm{~T}$ Trio with a 32-channel head coil. Visual stimuli are presented on a liquid-crystal display (LCD) screen (BOLDScreen 32; Cambridge Research Systems, Rochester, UK) visible to 
the participants through a mirror attached to the head coil. Physiological measures such as pulse and respiration are collected using BIOPAC. Each participant has two MRI scans, the first in week 1 (i.e. before randomisation) and the second during week 4.

Analyses will implement methods from the Centre for Functional MRI of the Brain (FMRIB) Statistical Library (FSL) [57]. Resting state connectivity will be investigated using independent component analysis (ICA) with the Multivariate Exploratory Linear Decomposition into Independent Components (MELODIC) tool. Evaluation of the resulting independent components will be used to compare neural networks of interest in the drug and placebo groups. We will apply a number of other FSL tools, including the fMRI Expert Analysis Tool (FEAT), an interface for model-based analysis of task fMRI based on general linear modelling (GLM). We will also utilise novel approaches being established by colleagues at the Wellcome Centre for Integrative Neuroimaging.

\section{Magnetoencephalography}

Magnetoencephalography (MEG) is included in OxCaMS for three reasons. First, its temporal resolution and ability to detect rapid neural oscillations and transient networks [58] make it well suited to investigate whether these domains are affected by LTCC antagonism. Second, the MEG signal derives directly from neuronal activity, free of the potential vascular confounds of the BOLD signal in fMRI. Third, the MEG signal arises primarily from the synchronised excitatory post-synaptic potentials generated in cortical pyramidal neurons, and the LTCCs targeted by nicardipine are primarily expressed on neuronal dendrites and influence their depolarisation. Hence, a change in MEG signal can be interpreted as indicative of significant functional occupancy of neuronal LTCCs by nicardipine, serving as a marker of target engagement.

MEG data are acquired on a passively shielded Elekta Neuromag system with participants in the seated position. Visual stimuli are presented via a PROPixx projection system (VPixx). Visual fixation and blinks are monitored throughout the scan using an infrared eye tracker (Eyelink 1000). Electrocardiograms and electro-oculograms are collected to enable removal of physiological artefacts from the data during analysis. The MEG protocol begins with a 10-min, eyes open and fixated, resting state scan. Immediately following this, participants complete a precision working memory task combined with a retrocue manipulation, adapted from Mok et al. [59] ( $35 \mathrm{~min})$. They will also undergo a passive viewing task to induce visual gamma using a paradigm adapted from a previously published task [60] ( $15 \mathrm{~min}$ ) and complete a gripper task to measure cortico-muscular coherence $(\sim 15 \mathrm{~min})$. As with MRI, each participant has two MEG scans, the first in week 1 (i.e. before randomisation) and the second in week 4 .

Analysis of resting state MEG measurements will explore the effect of LTCC antagonism on oscillatory activity and the integrity of resting state functional networks in mood instability. Data will be interrogated in both sensor space and source space after applying a linearly constrained minimum variance beamformer. Metrics such as oscillatory power and peak frequency will be explored. Additionally, we will apply hidden Markov modelling to identify transient brain states and assess any effects of nicardipine upon the dynamics of states (e.g. frequency of state switching and their fractional occupancy). Differences in drug/placebo groups will be tested using GLM. We will also utilise novel analytical approaches to MEG being established by colleagues at the Wellcome Centre for Integrative Neuroimaging (see e.g. $[58,61])$.

\section{Final visit}

After 14 days of randomisation to nicardipine or placebo, participants attend a final visit. A number of procedures/measurements are repeated from the screening visit, including physical examination and vital signs, blood samples, ECG and re-administration of the questionnaires and cognitive testing (with the exception of the NART). The GENEActiv, blood pressure, ePatch and iPad devices will be collected. Return of nicardipine and placebo is carried out by Clinical Research Facility staff. Participants fill out a number of questionnaires assessing the tolerability and acceptability of all devices and questions assessing interpretation of the mood questionnaires and cognitive tasks. To test the success of blinding, participants are asked to guess their group allocation. The second MRI and MEG scans, as detailed previously, are repeated either at the final visit or in the week before this visit, dependent upon scanner and participant availability.

\section{Power and statistical approaches}

OxCaMS is an exploratory experimental medicine study, and we will investigate the effect of LTCC antagonism on a range of parameters. As the first study of its kind, no meaningful power calculations are possible. The planned sample size ( $n=20$ in each group) is intended to be feasible and is similar to those of many comparable experimental medicine studies in psychiatry, including one in which the effects of lithium carbonate on cognitive and neural markers in healthy volunteers were examined. This suggested a sample size of 40 with $80 \%$ power at alpha $=0.05$ (see also [62]). OxCaMS is larger than the other experimental studies which have used an LTCC antagonist to examine cerebral blood flow $(n=12$ [63], $n=8$ [64]) and MRI indices of brain hypoxia ( $n=$ 
17 [65]). OxCaMS is also of similar or greater size than the studies which have demonstrated the effects of nicardipine or other LTCC antagonists on gastrointestinal motility $(n=42$ [28], $n=12$ [66]) and pressor responses to exercise $(n=12[67])$.

The outcomes to be investigated are summarised in Table 2. The specified primary outcome is on cognitive stability, across the range of tasks described above. Key secondary outcomes comprise the effect of LTCC antagonism on mood and neural markers and their stability, on sleep and on the peripheral markers of calcium channels. In addition, participants will be genotyped for rs1006737, the index risk single nucleotide polymorphism within $C A C N A 1 C$, using a TaqMan assay. Risk and non-risk allele carriers differ in $\mathrm{Ca}_{V} 1.2$ expression and activity [68], and this may influence their response to LTCC antagonism [69]. Hence, although our power will be very limited, we will examine for effects of genotype in exploratory analyses. Participation in the study is not based on genotype, since the low frequency of the minor allele $(\sim 0.30)$ would make recruitment based on homozygosity unfeasible, given time and resources available.

Data will be inspected for normality. For data meeting this criterion, group (drug vs. placebo) comparisons for longitudinal measures will utilise repeated measures analysis of variance (ANOVA); simple between-group comparisons will be made using unpaired $t$ tests; correlations between variables will be explored using Pearson correlations. Data which are non-Gaussian will be explored for outliers, and either transformed or subjected to non-parametric analysis.

Our primary measure of instability for cognitive and mood indices will be the root mean square of successive differences, a widely used measure of instability (see e.g. $[70,71])$. We will also explore additional mathematical approaches for the evaluation of instability (e.g. entropy, time signatures). MRI and MEG analyses have been outlined above.

Table 2 Summary of outcome measures for OxCaMS

Primary outcome
The effect of L-type voltage-gated calcium channel (LTCC) antagon-
ism on cognitive instability
Secondary outcomes
The effect of LTCC antagonism on mood instability
The effect of LTCC antagonism on physical activity and sleep
The effect of LTCC antagonism on neural dynamics, at rest and
during task performance
The effect of LTCC antagonism on heart rate variability
The effect of LTCC antagonism on calcium channel expression and
calcium signalling
The effect of rs1006737 genotype and its interaction with LTCC
antagonism on the above measures

\section{Other issues}

Like other LTCC antagonists, nicardipine can produce a range of side effects, of which headache, flushing and ankle oedema are prominent. Side effects are reported in $11-14 \%$ of patients [72], but they are generally minor and transient and are less common with the SR formulation (Cardene SPC, Roche). Nevertheless, their occurrence may compromise the blindness of treatment allocation and may cause drop-outs.

We anticipate that some participants will meet diagnostic criteria for a psychiatric disorder, especially bipolar disorder. If so, the participant will be told and will receive information and advice. With the participant's consent, their general practitioner will also be informed. The criterion of exclusion due to harmful use of alcohol was introduced to help exclude subjects in whom mood instability is driven primarily by their use of alcohol. We realise that this is an imperfect criterion, and it means that our results may not generalise to the many people who have mood instability and who do have harmful use of alcohol and other substances.

We intend to publish all results of OxCaMS in open access journals. Brief summaries will be posted on our websites.

\section{Discussion}

OxCaMS will help establish whether a 14-day run of LTCC blockade produces effects on brain and behaviour when used in adults with mood instability and, if so, the nature of these effects. It is an exploratory study which examines a range of parameters and tests a number of hypotheses related to the proposed role of LTCCs in relevant domains of brain function. By its nature, it is not expected that definitive or clinically actionable results will arise; rather, OxCaMS is designed to provide findings which can help inform future studies of LTCC antagonists for psychiatric indications, as well as to show the feasibility of a high-intensity, multimodal experimental medicine study.

Demonstration of beneficial effects of nicardipine on any of the indices will encourage consideration of clinical trials to test LTCC antagonists in specific psychiatric patient groups. However, even if this is not observed, bear in mind that the current class of LTCC antagonists were developed specifically for their cardiovascular effects, and that much of the underlying pharmacology was carried out in rodents. It is increasingly clear that there are significant differences in the composition of LTCCs between brain and periphery and between rodents and humans; hence, it may be possible to develop modified drugs of this class which have a greater selectivity for, and efficacy at, neuronal LTCCs. In this context, OxCaMS will serve as a proof of principle as to whether a psychiatric 'signal' can be observed with existing LTCC 
antagonists, albeit one which is likely to be therapeutically suboptimal. More broadly, OxCaMS will provide an exemplar of how experimental medicine studies are one way in which the treatment potential of psychiatric genomic discoveries, in this instance regarding LTCC genes, can be investigated.

\section{Trial status}

The trial protocol is version 1.5, dated 23 May 2018.

Recruitment began on 19 December 2017; anticipated completion of recruitment is December 2019.

\section{Additional files}

Additional file 1: SPIRIT checklist. (DOCX $52 \mathrm{~kb}$ )

Additional file 2: Study protocol, current version. (DOCX 1508 kb)

Additional file 3: Ethical approval letter. (DOCX 846 kb)

\section{Abbreviations}

ASRM: Altman Self-Rating Mania Scale; ASL: Arterial spin labelling; AUDIT: Alcohol Use Disorders Identification Test; ETB: Emotional test battery; fMRI: Functional magnetic resonance imaging; LTCC: L-type calcium channel; MDQ: Mood Disorder Questionnaire; MEG: Magnetoencephalography; NART: National Adult Reading Test; PANAS: Positive and Negative Affect Schedule; QIDS-SR: Quick Inventory of Depressive Symptomatology (selfreport); SCI: Sleep Condition Indicator

\section{Acknowledgements}

We thank Ann Sharpley and Clare Williams for encapsulation, Alexander Irvine for True Colours platform support, and Paul Leeson for cardiological advice. We are grateful to staff in the Oxford cognitive health Clinical Research Facility, and staff at the Nuffield Department of Medicine FACS core facility, for their support and enthusiasm.

\section{Funding}

LC is funded by the Oxford Wellcome Clinical Doctorate Programme. EMT is a Royal Society University Fellow. The research is funded by the Wellcome Trust and National Institute for Health Research (NIHR) Oxford Health Biomedical Research Centre. The authors also acknowledge support from the NIHR Oxford cognitive health Clinical Research Facility. The Wellcome Centre for Integrative Neuroimaging is supported by core funding from the Wellcome Trust (203139/Z/16/Z). The views expressed are those of the authors and not necessarily those of the NHS, the NIHR or the Department of Health and Social Care.

The funders had no role in the design of the study and will not have any role during its execution, analyses, interpretation of the data or decision to submit results.

\section{Availability of data and materials}

Participant level data are held on a secure server. After the end of the study, data will be made available to suitable applicants on submission of an appropriate analysis plan to the Principal Investigator, subject to ethical approval.

\section{Authors' contributions}

LZA, LC, JRG, KEAS and PJH conceived the overall study design and developed the protocol. LZA, KEAS and PJH wrote the manuscript. AC, AS, HJ and JR contributed to design, workflow and recruitment. ACN and $\mathrm{CHH}$ provided neuroimaging and cognitive elements. $\mathrm{CH}$ provided digital platform development and support. AM and EMT provided biochemical and genetic components. PJH is the Chief Investigator. All authors read and approved the final manuscript.

\section{Ethics approval and consent to participate}

Study approved by NHS Oxford Research Ethics Committee C (17/SC/0029, IRAS 213212). Latest amendment approved 23 May 2018 (protocol version 1.5). (Additional file 3 ).

\section{Consent for publication}

Not applicable.

\section{Competing interests}

The authors declare that they have no competing interests.

\section{Publisher's Note}

Springer Nature remains neutral with regard to jurisdictional claims in published maps and institutional affiliations.

\section{Author details}

${ }^{1}$ Department of Psychiatry, University of Oxford, Warneford Hospital, Oxford OX3 7JX, UK. ²Oxford Health Foundation NHS Trust, Warneford Hospital, Oxford, UK. ${ }^{3}$ Oxford Centre for Human Brain Activity, Wellcome Centre for Integrative Neuroimaging, Warneford Hospital, Oxford, UK. ${ }^{4}$ Department of Experimental Psychology, University of Oxford, New Radcliffe House, Oxford, UK. ${ }^{5}$ Big Data Institute, University of Oxford, Old Road Campus, Oxford, UK.

Received: 11 July 2018 Accepted: 2 January 2019

Published online: 12 February 2019

References

1. Pazzaglia PJ, Post RM, Ketter TA, George MS, Marangell LB. Preliminary controlled trial of nimodipine in ultra-rapid cycling affective dysregulation. Psychiatry Res. 1993;49:257-72.

2. Levy NA, Janicak PG. Calcium channel antagonists for the treatment of bipolar disorder. Bipolar Disord. 2000;2:108-19.

3. Warsh J I Andreopoulos S, Li PP. Role of intracellular calcium signaling in the pathophysiology and pharmacotherapy of bipolar disorder: current status. Clin Neurosci Res. 2004:4:201-13.

4. Wasserman MJ, Corson TW, Sibony D, Cooke RG, Parikh SV, Pennefather PS, et al. Chronic lithium treatment attenuates intracellular calcium mobilization. Neuropsychopharmacology. 2004;29:759-69.

5. Cipriani A, Saunders K, Attenburrow M-J, Stefaniak J, Panchal P, Stockton S, et al. A systematic review of calcium channel antagonists in bipolar disorder and some considerations for their future development. Mol Psychiatry. 2016; 21:1324-32.

6. Heyes S, Pratt WS, Rees E, Dahimene S, Ferron L, Owen MJ, et al. Genetic disruption of voltage-gated calcium channels in psychiatric and neurological disorders. Prog Neurobiol. 2015;134:36-54.

7. Harrison PJ, Geddes JR, Tunbridge EM. The emerging neurobiology of bipolar disorder. Trends Neurosci. 2018:41:18-30.

8. Zamponi GW, Striessnig J, Koschak A, Dolphin AC. The physiology, pathology, and pharmacology of voltage-gated calcium channels and their future therapeutic potential. Physiol Rev. 2015;67:821-70.

9. Striessnig J, Pinggera A, Kaur G, et al. L-type $\mathrm{Ca}^{2+}$ channels in heart and brain. Wiley Interdiscip Rev Membr Transp Signal. 2014;3:15-38.

10. Hanyu H, Hirao K, Shimizu S, Iwamoto T, Kolzumi K, Abe K. Favourable effects of nilvadipine on cognitive function and regional cerebral blood flow on SPECT in hypertensive patients with mild cognitive impairment Nucl Med Commun. 2007;28:281-7

11. Tomassoni D, Lanari A, Silvestrelli G, Traini E, Amenta F. Nimodipine and its use in cerebrovascular disease: evidence from recent preclinical and controlled clinical studies. Clin Exp Hypertension. 2008;30:744-66.

12. Boal AH, Smith DJ, McCallum L, Muir S, Touyz RM, Dominiczak, et al. Monotherapy with major antihypertensive drug classes and risk of hospital admissions for mood disorders. Hypertension. 2016:68:1132-8.

13. Dudley JA, Weir RK, Yan TC, Grabozska EM, Grimme AJ, Amini S, et al. Antagonism of L-type Cav channels with nifedipine differentially affects performance of wildtype and NK1R-/- mice in the 5-Choice Serial Reaction-Time Task. Neuropharmacology. 2013;64:329-36.

14. Levy A, Kong RM, Stillman MJ, Shukitthale B, Kadar T, Rauch TM, et al. Nimodipine improves spatial working memory and elevates hippocampal acetylcholine in young rats. Pharmacol Biochem Behav. 1991;39:781-6. 
15. Quartermain D, DeSoria VG, Kwan A. Calcium channel antagonists enhance retention of passive avoidance and maze learning in mice. Neurobiol Learn Mem. 2001;75:77-90.

16. Quartermain D, Garcia DeSoria V. The effects of calcium channel antagonists on short- and long-term retention in mice using spontaneous alternation behavior. Neurobiol Learn Mem. 2001;76:117-24.

17. Broome MR, Saunders KEA, Harrison PJ, Marwaha S. Mood instability: significance, definition and measurement. Br J Psychiatry. 2015;207:283-5.

18. Harrison PJ, Cipriani A, Harmer CJ, Nobre AC, Saunders K, Goodwin GM, et al. Innovative approaches to bipolar disorder and its treatment. Ann N Y Acad Sci. 2016;1366:76-89.

19. McDonald KC, Saunders KEA, Geddes JR. Sleep problems and suicide associated with mood instability in the Adult Psychiatric Morbidity Survey, 2007. Aust N Z J Psychiatry. 2017;51:822-8.

20. Amenta F, Tomassoni D, Traini E, Mignini F, Veglio F. Nicardipine: a hypotensive dihydropyridine-type calcium antagonist with a peculiar cerebrovascular profile. Clin Exp Hypertens. 2008;30:808-26.

21. Amenta F, Mignini F, Rabbia F, Tomassoni D, Veglio F. Protective effect of anti-hypertensive treatment on cognitive function in essential hypertension: analysis of published clinical data. J Neurol Sci. 2002;203:147-51.

22. Grotta J, Spydell J, Pettigrew C, Ostrow P, Hunter D. The effect of nicardipine on neuronal function following ischemia. Stroke. 1986;17:213-9.

23. Alps BJ, Calder C, Hass WK, Wilson AD. Comparative protective effects of nicardipine, flunarizine, lidoflazine and nimodipine against ischaemic injury in the hippocampus of the Mongolian gerbil. Br J Pharmacol. 1988;93:877-83.

24. Gasior M, Kamiński R, Brudniak T, Kleinrok Z, Czuczwar SJ. Influence of nicardipine, nimodipine and flunarizine on the anticonvulsant efficacy of antiepileptics against pentylenetetrazol in mice. J Neural Transm. 1996;103:819-31.

25. Yamada S, Uchida S, Ohkura T, Kimura R, Yamaguchi M, Suzuki M, et al. Alterations in calcium antagonist receptors and calcium content in senescent brain and attenuation by nimodipine and nicardipine. J Pharmacol Exp Ther. 1996;277:721-7.

26. Lin M, Aladejebi $\mathrm{O}$, Hockerman GH. Distinct properties of amlodipine and nicardipine block of the voltage-dependent $\mathrm{Ca}(2+)$ channels $\mathrm{Ca}(\mathrm{v}) 1.2$ and $\mathrm{Ca}(\mathrm{v}) 2.1$ and the mutant channels $\mathrm{Ca}(\mathrm{v}) 1.2 /$ dihydropyridine insensitive and Ca(v)2.1/dihydropyridine sensitive. Eur J Pharmacol. 2011;670:105-13.

27. Sun WM, Edwards CA, Prior A, Rao SSC, Read NW. Effect of oral nicardipine on anorectal function in normal human volunteers and patients with irritable bowel syndrome. Dig Dis Sci. 1990;35:885-90.

28. Sheaves B, Porcheret K, Tsanas A, Espie CE, Foster RG, Freeman D, et al. Insomnia, nightmares, and chronotype as markers of risk for severe mental illness: results from a student population. Sleep. 2016;39:173-81.

29. Hirschfeld RM, Williams JB, Spitzer RL, Calabrese JR, Flynn L, Keck PE, et al. Development and validation of a screening instrument for bipolar spectrum disorder: the Mood Disorder Questionnaire. Am J Psychiatry. 2000;157:1873-5.

30. Hirschfeld RMA, Holzer C, Calabrese JR, Weissman M, Reed M, Davies M, et al. Validity of the mood disorder questionnaire: a general population study. Am J Psychiatry. 2003;160:178-80.

31. Zanarini MC, Vujanovic AA, Parachini EA, Boulanger JL, Frankenburg FR, et al. A screening measure for BPD: the McLean Screening Instrument for Borderline Personality Disorder (MSI-BPD). J Personal Disord. 2003;17:568-73.

32. Horne J, Ostberg O. A self-assessment questionnaire to determine morningness-eveningness in human circadian rhythms. Int J Chronobiol. 1976:4:97-110

33. Espie CA, Kyle SD, Hames P, Gardani M, Fleming L, et al. The Sleep Condition Indicator: a clinical screening tool to evaluate insomnia disorder. BMJ Open. 2014:4:3.

34. Bundesen C. A theory of visual attention. Psychol Rev. 1990;97:523-47.

35. Finke K, Schwarzkopf W, Müller U, Frodl T, Muller HJ, Schneider WX, et al. Disentangling the adult attention-deficit hyperactivity disorder endophenotype: parametric measurement of attention. J Abnorm Psychol. 2011;120:890-901.

36. McAvinue LP, Habekost T, Johnson KA, Kyllingsbaek S, Vangkilde S, Bundesen $C$, et al. Sustained attention, attentional selectivity, and attentional capacity across the lifespan. Atten Percept Psychophys. 2012;74:1570-82.

37. MCAvinue LP, Vangkilde S, Johnson KA, Habekost T, Kyllingsbaek S, Robertson $\mathrm{H}$, et al. The relationship between sustained attention, attentional selectivity, and capacity. J Cogn Psychol. 2012;24:313-28.

38. Habekost T. Clinical TVA-based studies: a general review. Front Psychol. $2015 ; 6: 1-18$
39. McAvinue LP, Vangkilde $S$, Johnson KA, Habekost T, Kyllingsbaek S, Bundesen C, et al. A componential analysis of visual attention in children with ADHD. J Atten Disord. 2015;19:882-94.

40. Harmer CJ, O'Sullivan U, Favaron E, Massey-Chase R, Ayres R, Reinecke A, et al. Effect of acute antidepressant administration on negative affective bias in depressed patients. Am J Psychiatry. 2009;166:1178-84.

41. Logan GD, Schachar RJ, Tannock R. Impulsivity and inhibitory control. Psychol Sci. 1997:8:60-4.

42. Strakowski SM, Fleck DE, DelBello MP, Adler CM, Shear PK, Kotwal R, et al. Impulsivity across the course of bipolar disorder. Bipolar Disord. 2010;12:285-97.

43. Farrell SM, Tunbridge EM, Braeutigam S, Harrison PJ. COMT Val ${ }^{158}$ Met genotype determines the direction of cognitive effects produced by catechol-O-methyltransferase inhibition. Biol Psychiatry. 2012;71:538-44.

44. Nelson HE, Willison J. National Adult Reading Test (NART). Windsor: NFERNelson; 1991.

45. Chun MM, Jiang Y. Contextual cueing: implicit learning and memory of visual context quides spatial attention. Cogn Psychol. 1998;36:28-71.

46. Watson D, Clark LA, Tellegen A. Development and validation of brief measures of positive and negative affect: the PANAS scales. J Pers Soc Psychol. 1988;54:1063-70.

47. Thompson ER. Development and validation of an internationally reliable short-form of the Positive and Negative Affect Schedule (PANAS). J CrossCult Psychol. 2007:38:227-42.

48. Rush AJ, Trivedi MH, Ibrahim HM, Carmody TJ, Arnow B, Klein DN, et al. The 16-item Quick Inventory of Depressive Symptomatology (QIDS), clinician rating (QIDS-C), and self-report (QIDS-SR): a psychometric evaluation in patients with chronic major depression. Biol Psychiatry. 2003;54:573-83.

49. Altman EG, Hedeker D, Peterson JL, Davis JM. The Altman Self-Rating Mania Scale. Biol Psychiatry. 1997;42:948-55.

50. Spitzer RL, Kroenke K, Williams JBW, Lowe B. A brief measure for assessing generalized anxiety disorder: the GAD-7. Arch Intern Med. 2006;166:1092-7.

51. EuroQol. EuroQol - a new facility for the measurement of health-related quality of life. Health Policy (New York). 1990;16:199-208.

52. Carr O, Saunders KEA, Tsanas A, Bilderbeck AC, Palmius N, Geddes JR, et al. Variability in phase and amplitude of diurnal rhythms is related to variation of mood in bipolar and borderline personality disorder. Sci Rep. 2018;8:1-11.

53. Robert V, Triffaux E, Paulet PE, Guery JC, Pelletier L, Savignac M. Protein kinase C-dependent activation of Cav1.2 channels selectively controls human TH2lymphocyte functions. J Allergy Clin Immunol. 2014;133:1175-83.

54. Badou A, Jha M, Matza D, Flavell RA. Emerging roles of L-type voltage-gated and other calcium channels in T lymphocytes. Front Immunol. 2013;4:243.

55. Goldsmith DR, Rapaport MH, Miller BJ. A meta-analysis of blood cytokine network alterations in psychiatric patients: comparisons between schizophrenia, bipolar disorder and depression. Mol Psychiatry. 2016;21: 1696-709.

56. Wendt ER, Ferry H, Greaves DR, Keshav S. Ratiometric analysis of Fura Red by flow cytometry: a technique for monitoring intracellular calcium flux in primary cell subsets. PLOS One. 2015;10:e0119532.

57. Smith SM, Jenkinson M, Woolrich MW, Beckmann CF, Behrens TEJ, Johansen-Berg $\mathrm{H}$, et al. Advances in functional and structural MR image analysis and implementation as FSL. Neurolmage. 2004;23:208-19.

58. Baker AP, Brookes MJ, Rezek IA, et al. Fast transient networks in spontaneous human brain activity. eLife. 2014;2014:1-18. https://doi.org/10. 7554/eLife.01867.

59. Mok RM, Myers NE, Wallis G, et al. Behavioural and neural markers of flexible attention over working memory in aging. Cereb Cortex. 2016;26:1831-42.

60. Hoogenboom N, Schoffelen JM, Oostenveld $R$, et al. Localizing human visual gamma-band activity in frequency, time and space. Neuroimage. 2006;29:764-73.

61. Vidaurre D, Quinn AJ, Baker AP, Smith SM, Behrens T, Smith PJP, et al. Spectrally resolved fast transient brain states in electrophysiological data. Neurolmage. 2016;126:81-95.

62. Saunders KEA, Cipriani A, Rendell J, Attenburrow M-J, Nelissen N, Bilderbeck AC, et al. Oxford Lithium Trial (OxLith) of the early affective, cognitive, neural and biochemical effects of lithium carbonate in bipolar disorder: study protocol for a randomised controlled trial. Trials. 2016;17:116.

63. Schmidt JF, Waldemar G, Vorstrup S, Andersen AR, Gjebris F, Paulson OB. Computerized analysis of cerebral blood flow autoregulation in humans: validation of a method for pharmacologic studies. J Cardiovasc Pharmacol. 1990;15:983-8. 
64. Canova D, Roatta S, Micieli G, Bosone D. Cerebral oxygenation and haemodynamic effects induced by nimodipine in healthy subjects. Funct Neurol. 2012;27:169-76.

65. Rowland MJ, Ezra M, Winkler A, et al. Calcium channel blockade with nimodipine reverses MRI evidence of cerebral oedema following acute hypoxia. J Cereb Blood Flow Metab. 2017. https://doi.org/10.1177/ $0271678 \times 17726624$.

66. Konrad-Dalhoff I, Baunnack AR, Rämsch KD, Ahr G, Kraft H, Schmitz H, et al. Effect of the calcium antagonists nifedipine, nitrendipine, nimodipine and nisoldipine on oesophageal motility in man. Eur J Clin Pharmacol. 1991;41:313-6.

67. Jones RI, Hornung RS, Sonecha T, Raftery EB. The effect of a new calcium channel blocker nicardipine on 24-hour ambulatory blood pressure and the pressor response to isometric and dynamic exercise. J Hypertens. 1983;1:85-9.

68. Yoshimizu T, Pan JQ, Mungenast AE, et al. Functional implications of a psychiatric risk variant within CACNA1C in induced human neurons. Mo Psychiatry. 2015;20:162-9.

69. Ostacher MJ, losifescu DV, Hay A, Blumenthal SR, Sklar P, Perlis RH. Pilot investigation of isradipine in the treatment of bipolar depression motivated by genome-wide association. Bipolar Disord. 2014;16:199-203.

70. Gershon A, Eidelman P. Affective intensity and instability: predictors of depression and functional impairment in bipolar disorder. J Behav Ther Exp Psychiatry. 2015;46:14-8

71. Tsanas A, Saunders K, Bilderbeck A, Palmius N, Goodwin G, De Vos M. Clinical insight into latent variables of psychiatric questionnaires for mood symptom self-assessment. JMIR Ment Health. 2017;4:e15.

72. Sorkin EM, Clissold SP. Nicardipine: a review of its pharmacodynamic and pharmacokinetic properties, and therapeutic efficacy, in the treatment of angina pectoris, hypertension and related cardiovascular disorders. Drugs. 1987;33:296-345

Ready to submit your research? Choose BMC and benefit from:

- fast, convenient online submission

- thorough peer review by experienced researchers in your field

- rapid publication on acceptance

- support for research data, including large and complex data types

- gold Open Access which fosters wider collaboration and increased citations

- maximum visibility for your research: over $100 \mathrm{M}$ website views per year

At $\mathrm{BMC}$, research is always in progress.

Learn more biomedcentral.com/submissions 